Biogeosciences, 10, 3691-3703, 2013

www.biogeosciences.net/10/3691/2013/

doi:10.5194/bg-10-3691-2013

(C) Author(s) 2013. CC Attribution 3.0 License.

\title{
A meta-analysis on the impacts of partial cutting on forest structure and carbon storage
}

\author{
D. Zhou ${ }^{1}$, S. Q. Zhao ${ }^{1}$, S. Liu ${ }^{2}$, and J. Oeding ${ }^{3}$ \\ ${ }^{1}$ College of Urban and Environmental Sciences, and Key Laboratory for Earth Surface Processes of the Ministry of \\ Education, Peking University, Beijing 100871, China \\ ${ }^{2}$ US Geological Survey (USGS) Earth Resources Observation and Science (EROS) Center, Sioux Falls, South Dakota 57198, \\ USA \\ ${ }^{3}$ Stinger Ghaffarian Technologies, Contractor to the USGS EROS Center, Sioux Falls, South Dakota 57198, USA
}

Correspondence to: S. Q. Zhao (sqzhao@urban.pku.edu.cn)

Received: 3 January 2013 - Published in Biogeosciences Discuss.: 14 January 2013

Revised: 6 May 2013 - Accepted: 9 May 2013 - Published: 5 June 2013

\begin{abstract}
Partial cutting, which removes some individual trees from a forest, is one of the major and widespread forest management practices that can significantly alter both forest structure and carbon (C) storage. Using 748 observations from 81 studies published between 1973 and 2011, we synthesized the impacts of partial cutting on three variables associated with forest structure (mean annual growth of diameter at breast height (DBH), stand basal area, and volume) and four variables related to various $\mathrm{C}$ stock components (aboveground biomass $\mathrm{C}$ (AGBC), understory $\mathrm{C}$, forest floor $\mathrm{C}$, and mineral soil $\mathrm{C}$ ). Results show that the growth of DBH increased by $111.9 \%$ after partial cutting, compared to the uncut control, with a $95 \%$ bootstrapped confidence interval ranging from 92.2 to $135.9 \%$, while stand basal area and volume decreased immediately by $34.2 \%$ $([-37.4 \%,-31.2 \%])$ and $28.4 \%([-32.0 \%,-25.1 \%])$, respectively. On average, partial cutting reduced AGBC by $43.4 \%$ ([-47.7\%, -39.3\%]), increased understory C storage by $391.5 \%$ ([220.0\%, 603.8\%]), but did not show significant effects on $\mathrm{C}$ stocks on forest floor and in mineral soil. All the effects, if significant (i.e., on DBH growth, stand basal area, volume, and AGBC), intensified linearly with cutting intensity and decreased linearly over time. Overall, cutting intensity had more strong impacts than the length of recovery time on the responses of those variables to partial cutting. Besides the significant influence of cutting intensity and recovery time, other factors such as climate zone and forest type also affected forest responses to partial cutting. For example, a large fraction of the changes in DBH growth re-
\end{abstract}

mains unexplained, suggesting the factors not included in the analysis may play a major role. The data assembled in this synthesis were not sufficient to determine how long it would take for a complete recovery after cutting because long-term experiments were scarce. Future efforts should be tailored to increase the duration of the experiments and balance geographic locations of field studies.

\section{Introduction}

Forests cover $31 \%$ of the total land area globally and play a major role in the global carbon (C) cycle (FAO, 2010; Pan et al., 2011). They experience various disturbances, often with increasing frequency and severity unseen in recorded history (Asner et al., 2005; DeFries et al., 2010; Masek et al., 2011). Partial cutting, one of the major forest management activities in many regions of the world (Houghton, 2005; Peres et al., 2006), removes some tree individuals from forests to serve various purposes including enhancement of wood production, management of species composition and stand structure, and reduction of fire risk (Kolb et al., 1998; Harvey et al., 2002; Frey et al., 2003; McDowell et al., 2006; Campbell et al., 2009). Partial cutting is known to cause significant impacts on both forest structure and functions (Reich, 2011; Goetz et al., 2012). It can alter tree spacing, density, and size distribution, and affect carbon exchange between the biosphere and the atmosphere (Vesala et al., 2005; Dwyer et al., 2010; Huang and Asner, 2010). 
The impact of forest cutting, especially partial cutting, has been identified as one of the major knowledge gaps in regional and global C accounting (Liu et al., 2011; Goetz et al., 2012). Most studies have been performed at plot scale (e.g., Bunker et al., 2005; Vargas et al., 2009; Navarro et al., 2010), and the experimental results from individual studies are highly variable mainly because of the differences in cutting intensity and number of recovery years after cutting. For example, some studies reported substantial increases in the growth of tree diameter at breast height (DBH) (Guariguata, 1999; Vesala et al., 2005), stand basal area (Vargas et al., 2009), tree volume (Curtis et al., 1997; Smith, 2003), and some C stocks (Lee et al., 2002; Kunhamu et al., 2009; Horner et al., 2010; Navarro et al., 2010) following partial cutting, whereas many showed insignificant or opposite impacts on these forest properties (Sawadogo et al., 2005; Chan et al., 2006; Lindquist, 2007; Peña-Claros et al., 2008; Skovsgaard, 2009; Campbell et al., 2009). The diversified and seemly inconsistent results across various studies preclude our comprehensive understanding of forest cutting and hinder the extrapolation of experimental results to predict longterm change of forest ecosystem and $\mathrm{C}$ dynamics at regional and global scales (Luo et al., 2006).

To our knowledge, two syntheses examining the changes of soil C stock after forest cutting in temperate forests (Nave et al., 2010) and global forests (Johnson and Curtis, 2001) have been conducted to date. Both studies found the change of soil carbon in mineral soils was insignificant. The $\mathrm{C}$ storage on the forest floor either decreased (Nave et al., 2010) or changed insignificantly (Johnson and Curtis, 2001) following forest cutting. Nevertheless, these two syntheses concentrated on soil $\mathrm{C}$ dynamics, and their focus was on clear cutting rather than partial cutting. Apparently, a comprehensive assessment on the impacts of partial cutting on the structure and $\mathrm{C}$ dynamics in forest ecosystems is needed for a better understanding and quantification of its role in the $\mathrm{C}$ cycle (Pregitzer and Euskirchen, 2004; Huang and Asner, 2010; Goetz et al., 2012).

In this paper, we analyzed and synthesized 748 observations from 81 field studies published between 1973 and 2011 and examined changes in various forest structural characteristics and $\mathrm{C}$ stock components induced by partial cutting. In addition to assess their general change directions and magnitudes after partial cutting, the relationships of these changes with multiple factors, such as cutting intensity, number of recovery years, forest types and climate zones were further analyzed to explore the possible causes of their responses' variability.

\section{Methods}

\subsection{Data sources}

Data were collected from relevant scientific papers published by the end of December 2011. We searched the online databases Web of Knowledge (http://isiknowlegde.com) and Google scholar (http://scholar.google.com) for available papers published in the English language using keywords "thinning," "selective cutting," "partial cut," "harvesting," "management treatment," or "silvicultural treatment" (in title, abstract, or keywords) and theme "forest". The following three criteria were used to select data from papers for this synthesis. First, studies without control (i.e., an uncut forest plot) were excluded. Without control plots, it is impossible to do the paired comparison to analyze the relative changes induced by partial cutting over time. Second, modeling studies were excluded because our synthesis was based on field observations. Finally, papers that did not report CI (cutting intensity) and those dealing with repeated cuttings were also excluded. After scanning all the papers returned, we compiled a database of 81 papers published between 1973 and 2011 that reported the impacts of partial cutting on either the forest structure and/or C storage (Fig. S1).

Cutting intensity has been defined differently in the collected 81 publications, using either the amount of volume, stand basal area, or stems removed from or left in the stand. In this paper, we define cutting intensity as the removed (not remaining) fraction of volume, stand basal area, or stems in the stand during cutting operations. If the intensity is defined otherwise in the original papers, we have converted it to our definition.

The raw data were either extracted from published tables or obtained by digitizing published graphs using GetData Graph Digitizer 2.24 (free software downloaded from http: //getdata-graph-digitizer.com). The final constructed dataset consists of 748 observations, with the longest recovery time being $42 \mathrm{yr}$ after cutting. It includes three variables associated with forest structure (annual mean DBH growth, stand basal area, and volume) and four variables related to various $\mathrm{C}$ stock components (aboveground biomass $\mathrm{C}$ (AGBC), understory $\mathrm{C}$ storage, forest floor $\mathrm{C}$, and mineral soil $\mathrm{C}$ ) (Table S1). We defined the depth of mineral soil as $0-15 \mathrm{~cm}$ in this analysis because about $82 \%$ of the studies reported the soil $\mathrm{C}$ sampled in this layer. The other studies (i.e., Yang et al., 2001; Gundale et al., 2005) that provided soil $\mathrm{C}$ at the depth of $0-10 \mathrm{~cm}$ were also utilized directly without further transformation in order to include as many observations as possible. In addition, each record includes information regarding its geographic location (longitude and latitude), climate information (tropical, subtropical, Mediterranean, temperate continental, temperate maritime, and boreal), forest type (coniferous, broadleaf, and mixed), and definition of cutting intensity (defined by stem number, stand basal area, or volume) which were easily extracted from the 
publications. If the paper did not report the climate information, we determined it according to the geographic location of the study sites.

\subsection{Meta-analysis}

The percent relative change (RC) in any of the seven variables following partial cutting was calculated as follows (Laganière et al., 2010; Power et al., 2011):

$\mathrm{RC}=\left(\mathrm{CUT}_{t}-\mathrm{CON}_{t}\right) / \mathrm{CON}_{t} \cdot 100$,

where $\mathrm{CUT}_{t}$ is the value of a given variable from the cutting stand at time $t$, and $\mathrm{CON}_{t}$ is the value from the control at time $t$. Thus, negative RC indicates a negative response to partial cutting and positive RC indicates a positive response.

Many of the studies did not report any measure of variance for the response variables that we were interested in. Thus, in order to include as many studies as possible, an unweighted meta-analysis was used in this paper, in which the response effects were not weighted by sample size (Gurevitch and Hedges, 2001; Guo and Gifford, 2002). The nonparametric resampling was utilized to generate bias-corrected bootstrapped approximate $95 \%$ confidence intervals from 1000 randomizations in SPSS PASW Statistics 18 (SPSS Inc.). The estimated effects were considered statistically different from zero if the zero did not fall into the $95 \%$ confidence interval, and the two effects were considered significantly different if the confidence intervals of them did not overlap.

To investigate the impacts of cutting intensity on forest properties, all data were grouped into three intensity categories: light $(<34 \%)$, moderate $(34-67 \%)$, and heavy $(\geq 67 \%$ ). We further examined the recovery of these properties after cutting practices by grouping the observations into three recovery years according to the number of years after cutting: short ( $\leq 5 \mathrm{yr}$ ), medium (5-10 yr), and long ( $>10 \mathrm{yr}$ ) experiments. We put all experiments longer than $10 \mathrm{yr}$ into one category because there were not enough observations in this category to divide it further. These grouped analyses were performed on the variables with sufficient observations (i.e., DBH growth, stand basal area, volume, and AGBC).

To determine if including other biophysical factors (in addition to cutting intensity and recovery time) can reduce unexplained variation in the observed responses, we examined the relationships between the relative changes and the other underlying factors including climate zone, forest type, and definition of cutting intensity (using stand basal area, volume, or stems) for all the four variables with sufficient observations (i.e., DBH growth, stand basal, volume, and AGBC). For the convenience of quantitatively estimating their relationship, we treated these categorical factors (i.e., climate zone, forest type, and cutting intensity definition) as dummy variables (Gujarati, 1970). Because cutting intensity and recovery time may play a dominant role in both the overall changes and the recovery of some variables like stand basal area and biomass after partial cutting (Scheller et al., 2011), they may overshadow the impact of the other factors on the general response patterns. To reduce this effect, we calculated the partial correlation coefficients between all of these dummy variables and relative changes while holding cutting intensity and recovery time as the control variables in SPSS PASW Statistics 18 (SPSS Inc.).

\section{Results}

\subsection{Overall direction and magnitude of the changes in forest structure and $\mathrm{C}$ stocks}

The relative changes of various forest structural attributes and $\mathrm{C}$ stock components following partial cutting varied in direction and magnitude (Fig. 1 and Table 1). For stand basal area and volume, a negative effect was the most frequently observed pattern. By contrast, a positive effect was mostly observed in DBH growth. Overall, partial cutting decreased stand basal area and volume significantly by 34.2 and $28.4 \%$, with $95 \%$ bootstrapped confidence intervals ranging from -37.4 to $-31.2 \%$ and -32.0 to $-25.1 \%$, respectively, but increased DBH growth by $111.9 \%$ ([92.2\%, 135.9\%]) relative to the uncut controls in our compiled dataset. Closely related to the structure dynamics, the $\mathrm{C}$ stored in AGBC decreased significantly by $43.4 \%$ ([-47.7\%, $-39.3 \%])$, while the $\mathrm{C}$ stored in understory increased substantially by $391.5 \%$ ([220.0\%, 603.8\%]), compared with the uncut controls. However, decreases in the $\mathrm{C}$ stocks of both forest floor (reduced by $9.2 \%([-23.4 \%, 3.5 \%]), P=0.18)$ and mineral soil (reduced by $2.9 \%$ ([-9.5\%, 3.6\%]), $P=0.37$ ) were not significant. Large variances were observed in the relative changes of DBH growth and the $\mathrm{C}$ stored in understory across study sites.

\subsection{Factors affecting the responses of forest structure and $\mathrm{C}$ pools to partial cutting}

Cutting intensity and recovery time had significant impacts on the response of all variables (except $\mathrm{C}$ stored in forest floor and mineral soil) to partial cutting (Fig. S2 and Table 2). Specifically, cutting intensity had a significant and negative correlation with stand basal area, volume, and AGBC, while the recovery time related significantly and positively to all of them. By contrast, the relative changes of DBH growth and understory $\mathrm{C}$ storage were positively correlated with cutting intensity, and negatively with recovery years. In addition, Table 2 shows that cutting intensity had more strong impacts than the length of recovery time on the responses of those variables (except AGBC) to partial cutting $(r=0.23,-0.64$, -0.67 , and 0.60 vs. $-0.18,0.27,0.26$, and -0.12 for the relationships of cutting intensity and the length of recovery time with DBH growth, stand basal area, volume, and understory C stocks, respectively). In fact, most of the statistically significant correlation coefficients between recovery time and percent of relative changes of the above variables (except 
Table 1. Mean values of the relative changes (\%) for the seven variables related to forest structure and carbon (C) storage, grouped by cutting intensity classes if available.

\begin{tabular}{|c|c|c|c|c|c|c|}
\hline Indicators & $\begin{array}{l}\text { CI } \\
\text { classes }\end{array}$ & $\begin{array}{l}\text { Mean relative change }(\%) \\
\text { (lower and upper } 95 \% \\
\text { bootstrapped confidence } \\
\text { intervals) }\end{array}$ & $\begin{array}{r}\text { CI (\%) } \\
(\text { mean } \pm \text { SE) }\end{array}$ & $\begin{array}{r}\mathrm{RY} \\
(\text { mean } \pm \mathrm{SE})\end{array}$ & $\begin{array}{r}\text { Number } \\
\text { of } \\
\text { observations }\end{array}$ & $\begin{array}{r}\text { Number } \\
\text { of } \\
\text { studies }\end{array}$ \\
\hline \multirow[t]{4}{*}{ DBH growth } & Light & $66.9(46.6,90.2)$ & $18.9 \pm 1.2$ & $11.9 \pm 1.1$ & 65 & 15 \\
\hline & Moderate & $102.0(82.7,121.3)$ & $49.3 \pm 1.0$ & $8.3 \pm 0.8$ & 79 & 22 \\
\hline & Heavy & $169.8(120.2,229.2)$ & $83.2 \pm 0.9$ & $14.1 \pm 1.3$ & 64 & 12 \\
\hline & All & $111.9(92.2,135.9)$ & $50.2 \pm 1.9$ & $11.2 \pm 0.6$ & 208 & 31 \\
\hline \multirow[t]{4}{*}{ Stand BA } & Light & $-15.2(-18.2,-11.8)$ & $22.7 \pm 0.7$ & $8.7 \pm 0.7$ & 94 & 24 \\
\hline & Moderate & $-37.3(-39.8,-34.8)$ & $48.9 \pm 0.9$ & $8.0 \pm 0.7$ & 101 & 27 \\
\hline & Heavy & $-68.3(-72.6,-64.3)$ & $80.2 \pm 1.3$ & $9.5 \pm 1.2$ & 46 & 13 \\
\hline & All & $-34.2(-37.4,-31.2)$ & $44.5 \pm 1.4$ & $8.5 \pm 0.5$ & 241 & 35 \\
\hline \multirow[t]{4}{*}{ Volume } & Light & $-20.8(-25.1,-16.6)$ & $22.2 \pm 1.2$ & $10.4 \pm 1.1$ & 50 & 12 \\
\hline & Moderate & $-29.6(-32.5,-26.7)$ & $43.7 \pm 1.3$ & $8.9 \pm 1.2$ & 32 & 11 \\
\hline & Heavy & $-62.6(-67.1,-58.6)$ & $75.9 \pm 1.1$ & $10.6 \pm 2.8$ & 10 & 4 \\
\hline & All & $-28.4(-32.0,-25.1)$ & $35.5 \pm 2.0$ & $9.9 \pm 0.8$ & 92 & 15 \\
\hline \multirow[t]{4}{*}{ AGBC } & Light & $-28.2(-36.1,-20.3)$ & $26.0 \pm 1.2$ & $7.4 \pm 1.2$ & 20 & 8 \\
\hline & Moderate & $-42.2(-46.4,-27.9)$ & $53.1 \pm 1.6$ & $5.3 \pm 0.7$ & 48 & 18 \\
\hline & Heavy & $-49.2(-56.3,-42.0)$ & $87.9 \pm 1.1$ & $11.9 \pm 1.4$ & 62 & 11 \\
\hline & All & $-43.4(-47.7,-39.3)$ & $65.6 \pm 2.2$ & $8.8 \pm 0.8$ & 130 & 26 \\
\hline Understory $\mathrm{C}$ & All & $391.5(220.0,603.8)$ & $60.5 \pm 2.4$ & $3.9 \pm 0.4$ & 19 & 4 \\
\hline Forest floor C & All & $-9.2(-23.4,3.5)$ & $41.4 \pm 3.5$ & $5.0 \pm 1.0$ & 30 & 12 \\
\hline Mineral soil C & All & $-2.9(-9.5,3.6)$ & $42.0 \pm 3.4$ & $3.5 \pm 0.6$ & 28 & 11 \\
\hline
\end{tabular}

Significant transitions, inferred as approximate $95 \%$ bootstrapped confidence intervals (based on 1000 bootstrap samples) that contain 0 , are in bold, which suggests the relative changes in the variable was insignificant compared to the uncut control.

Light, moderate, and heavy cutting were defined by the cutting intensity of $<34 \%, 34-67 \%$, and $>67 \%$, respectively.

DBH growth, growth of diameter at breast height; BA, basal area; AGBC, aboveground biomass C; CI, cutting intensity; RY: recovery years since cutting activities; SE, standard error.

AGBC) were less than 0.3, indicating an overall weak explanation power of recovery time to forest responses to partial cutting. Furthermore, the correlation coefficient between the cutting intensity and the changes in DBH growth was much lower than that in other variables, suggesting there existed other factors responsible for its variations across studies. As for the relationships between cutting intensity or recovery time and forest floor $\mathrm{C}$ or mineral soil $\mathrm{C}$, all the correlations were not significant.

Factors other than cutting intensity and recovery time also contributed to the observed variations in both forest structure and $\mathrm{C}$ pools (Table 2). For the two variables with sufficient observations (i.e., DBH growth and stand basal area), our results show that the positive effect of partial cutting on DBH growth was more intensive in the broadleaf trees than in conifer ones compared with the uncut controls $(r=0.22, P<0.01)$ (Fig. 2 and Table 2$)$ probably because of the greater light improvement for the remaining trees in broadleaf forests compared to coniferous forests after partial cutting (Hale, 2003). Nevertheless, the changes in stand basal area after partial cutting did not differ significantly with for- est type (Fig. 2 and Table 2), most likely due to its strong dependence on cutting intensity (Scheller et al., 2011). We found the increase in DBH growth was lower in subtropical forests than that in most others $(r=-0.24, P<0.01)$ (Fig. 3 and Table 2), which can also be mainly explained by relatively lower light enhancement for the remaining trees in subtropical forests compared to other forests after cutting practices (Hale, 2003). In addition, the changes of DBH growth and stand basal area were overall weaker in boreal forests relative to most other regions (Fig. 3 and Table 2), probably due to the lower vegetation productivity under this climate condition. It is interesting to notice that the definition of cutting intensity was closely linked to the relative changes in DBH growth, stand basal area, volume, and AGBC, indicating that cutting intensity definition can strongly influence study results (Table 2). However, the correlation coefficients (between forest type, climate zone, or cutting intensity definition and the changes in variables) estimated in this analysis were less than 0.4 for most cases, suggesting their relatively small contribution to the forest responses' variability across study sites. 


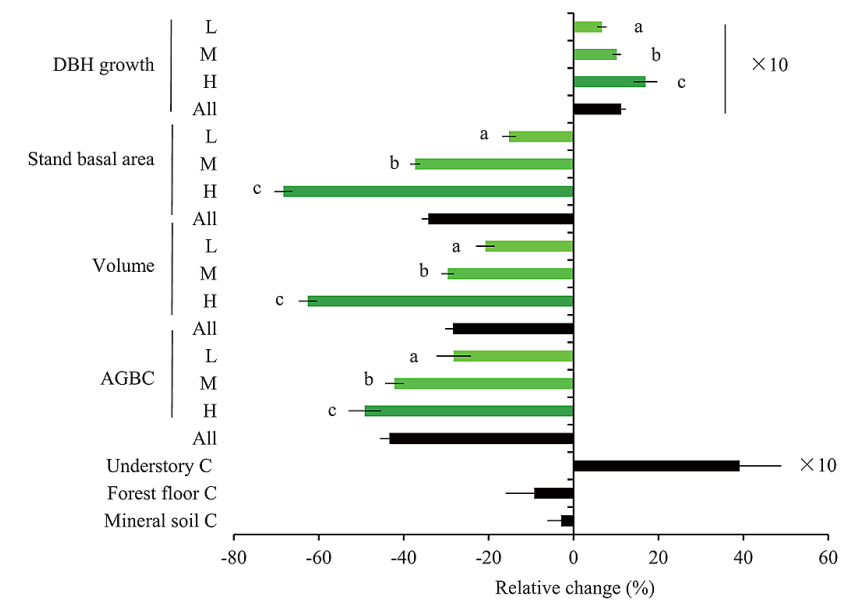

Fig. 1. Overall directions and magnitudes of the relative changes (\%) in the growth of diameter at breast height (DBH growth), stand basal area, volume, aboveground biomass C (AGBC), understory $\mathrm{C}$ storage, forest floor $\mathrm{C}$, and mineral soil $\mathrm{C}$ after partial cutting, compared to the uncut control. The error bars are the standard error (SE). The results of one-way ANOVA $(P<0.05)$ among three cutting intensity (CI) groups (light (L): $\mathrm{CI}<34 \%$; moderate (M): $34 \% \leq \mathrm{CI}<67 \%$; and heavy $(\mathrm{H}): \mathrm{CI} \geq 67 \%)$ are shown beside the error bars, with a different letter meaning a difference significant at $P<0.05$. The values on the $\mathrm{x}$-axis for DBH growth and understory $\mathrm{C}$ are 10 times those of other variables.

\subsection{Impacts of cutting intensity and recovery time}

As illustrated above, cutting intensity had statistically significant impacts on the relative change of DBH growth, stand basal area, volume, and AGBC, the four variables with sufficient observations (Table 2). Overall, the relative changes in DBH growth increased linearly with cutting intensity $(r=$ $0.31, P<0.01)$ but with a large variation among individual studies $(\mathrm{SE}=79 \%)$, especially when the number of recovery years $<5 \mathrm{yr}$ (Fig. 4 ). In contrast, the relative changes decreased linearly in stand basal area $(r=-0.88, P<0.01)$ and volume $(r=-0.67, P<0.01)$, with the largest slope and the most significant tendency in the short term (recovery years $<5 \mathrm{yr}$ ). The change pattern for the AGBC was similar to that of the two structural metrics (stand basal area and volume) and exhibited a significantly decreasing trend over the low-high cutting intensity gradient $(r=-0.39, P<0.01)$ (Fig. 4).

The trend along the recovery time gradient reflects ecosystem recovery patterns after disturbance (Fig. 5). Overall, the magnitude of the relative changes induced by partial cutting decreased with the increase of recovery years as shown by a decreasing trend in both the positive effects on DBH growth and the negative effects on stand basal area, volume, and AGBC. The recovery or return of these variables to uncut levels depended strongly on disturbance intensity, and the recovery time was positively related to cutting intensity

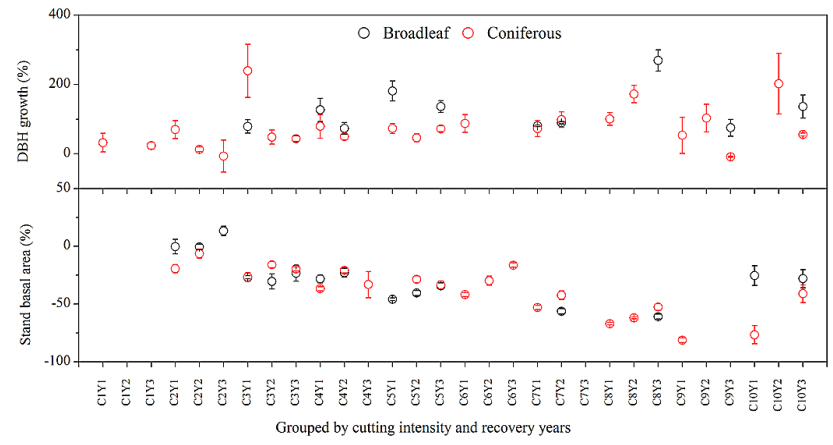

Fig. 2. Scatterplots of the mean relative changes (\%) of DBH growth and stand basal area for different forest types (i.e., broadleaf and coniferous) grouped by cutting intensity and recovery years when there are three or more observations for the group. The error bars are the standard deviation (SD). $\mathrm{C} 1$ to $\mathrm{C} 10$ represent the cutting intensity levels ranging from $0-10$ to $90-100$ with $10 \%$ intervals. $\mathrm{Y} 1, \mathrm{Y} 2$, and $\mathrm{Y} 3$ indicate the number of recovery years of $0-5,5-10$, and $>10$ yr., respectively.

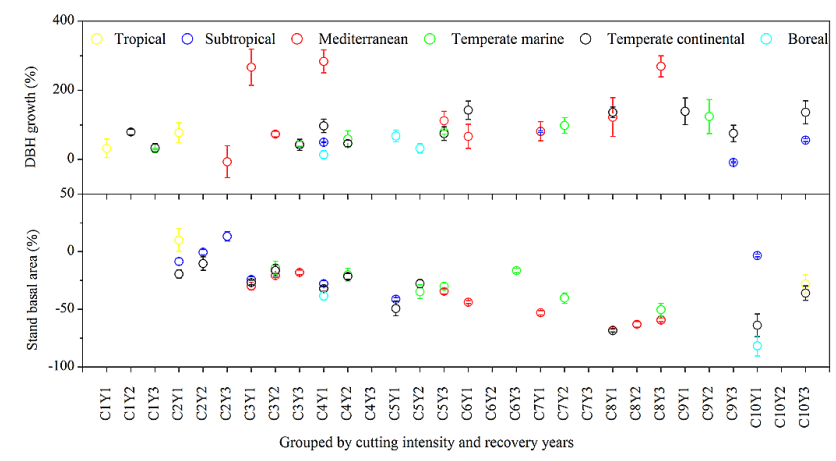

Fig. 3. Scatterplots of the mean relative changes (\%) of DBH growth and stand basal area for different climatic zones (i.e., tropical, subtropical, Mediterranean, temperate marine, temperate continental, and boreal) grouped by cutting intensity and recovery years when there are three or more observations for the group.

(Fig. 5). The recovering trends, indicated by the slopes of the regression, were statistically significant for stand basal area $(P<0.01)$, volume $(P<0.01)$, and AGBC $(P<0.01)$, but not for DBH growth $(P=0.43)$.

In addition, the trends of the ecosystem recovery varied with the cutting intensity for different variables. A statistically significant decreasing trend in the relative change of DBH growth was observed along recovery years under light cutting $(r=-0.25, P<0.05)$, whereas the trends under moderate $(P=0.53)$ and heavy cutting $(P=0.50)$ were not significant. In contrast, the recovering trend in AGBC under light cutting was not significant $(P=0.63)$ but those under moderate $(P<0.05)$ and heavy $(P<0.01)$ cuttings were significant. The insignificant recovery trends of DBH growth and AGBC under certain cutting intensity classes can be attributed partially to the uneven data distribution of them 
Table 2. Partial correlation coefficients between relative changes of the seven variables (related to forest structure and C storage) and potential driving factors.

\begin{tabular}{|c|c|c|c|c|c|c|c|c|c|c|c|c|}
\hline Indicator & CI & RY & $\mathrm{C}_{1}$ & $\mathrm{C}_{2}$ & $\mathrm{C}_{3}$ & $\mathrm{C}_{4}$ & $\mathrm{C}_{5}$ & $\mathrm{~F}_{1}$ & $\mathrm{~F}_{2}$ & $\mathrm{DCI}_{1}$ & $\mathrm{DCI}_{2}$ & df \\
\hline DBH growth & $0.23^{* *}$ & $-0.18^{*}$ & $-0.24^{* *}$ & $0.33^{* *}$ & -0.01 & -0.06 & $-0.15^{*}$ & - & $0.22 * *$ & $0.23^{* *}$ & $-0.28^{* *}$ & 201 \\
\hline Stand BA & $-0.64^{* *}$ & $0.27^{* *}$ & $-0.20^{* *}$ & -0.05 & -0.05 & $0.35^{* *}$ & $-0.16^{*}$ & $-0.16^{*}$ & 0.03 & $0.21^{* *}$ & $-0.17^{* *}$ & 238 \\
\hline Volume & $-0.67^{* *}$ & $0.26^{*}$ & - & $0.22^{*}$ & 0.09 & -0.10 & $0.22^{*}$ & - & -0.21 & $0.63^{* *}$ & -0.03 & 89 \\
\hline AGBC & $-0.69^{* *}$ & $0.77^{* *}$ & 0.09 & -0.06 & $-0.22^{*}$ & $0.37^{* *}$ & 0.07 & - & 0.10 & -0.08 & $0.36^{* *}$ & 126 \\
\hline Understory C & $0.60^{* *}$ & -0.12 & - & - & - & - & - & - & - & - & - & - \\
\hline Forest floor C & -0.07 & -0.31 & - & - & - & - & - & - & - & - & - & - \\
\hline Mineral soil C & -0.06 & -0.24 & - & - & - & - & - & - & - & - & - & - \\
\hline
\end{tabular}

* Correlation is significant at the 0.05 level (2-tailed); $* *$ correlation is significant at the 0.01 level (2-tailed). df is the degrees of freedom.

$\mathrm{C}_{1} \sim \mathrm{C}_{5}$ : dummy variables for climate zone where tropical was considered the base climate zone. $\mathrm{C}_{1}(=1$ if is subtropical, $=0$, otherwise $), \mathrm{C}_{2}(=1$ is $\mathrm{Mediterranean},=0$, otherwise), $\mathrm{C}_{3}(=1$ if is temperate marine, $=0$, otherwise $), \mathrm{C}_{4}(=1$ if is temperate continental, $=0$, otherwise $), \mathrm{C}_{5}(=1$ if is boreal, $=0$, otherwise).

$\mathrm{F}_{1} \sim \mathrm{F}_{2}$ : dummy variables for forest type where coniferous was taken as the base forest type. $\mathrm{F}_{1}\left(=1\right.$ if lies in mixed group, $=0$, otherwise), $\mathrm{F}_{2}(=1$ if lies in broadleaf group, $=0$, otherwise).

$\mathrm{DCI}_{1} \sim \mathrm{DCI}_{2}$ : dummy variables for the definition of cutting intensity where definition by stems number was considered the base definition. DCI $(=1$ if defined by basal area, $=0$, otherwise), $\mathrm{DCI}_{2}$ (=1 if defined by volume, $=0$, otherwise).

along recovery year sequences (Fig. 5) and in part to the relatively small explanation power of recovery time to their observed variances across study sites (Table 2). The relative changes in both stand basal area and volume increased significantly as recovery time became longer under all cutting intensity groups.

General linear models (Gujarati, 1970) were developed to investigate whether the responses of forests to partial cutting can be predicted using the variables in the dataset (Table 3). Our linear models only explained a small fraction of the relative change of DBH growth. In contrast, the explanatory power of the models for the relative changes in stand basal area, volume, and AGBC using cutting intensity and recovery time as independent variables were 43,48 , and $65 \%$, respectively, and improved to 65,76 , and $76 \%$, respectively, when adding three more independent variables (forest type, climatic zone, and cutting definition). These results suggest that the effects of partial cutting on a forest ecosystem can be mainly explained by cutting intensity and recovery time, and was significantly contributed by other factors (e.g., climate zone, forest type, and cutting definition) as well in terms of stand basal area, volume and biomass, yet some variables not included in this study may play a major role in the relative change of DBH growth.

\section{Discussion}

\subsection{Forest structure change after partial cutting}

Our synthesis indicates that partial cutting stimulates the growth of residual trees significantly, in spite of large variations among cutting intensities, recovery years, and site conditions, which corresponds to the general notion that partial cutting reduces individual competition and thus should have a positive effect on residual tree growth (Walter and Maguire, 2004; Vesala et al., 2005; Navarro et al., 2010).
Overall, the relative changes of DBH growth correlated positively with the increase of cutting intensity, which was also comparable to many individual studies (Juodvalkis et al., 2005; Peña-Claros et al., 2008). Moreover, we found an overall declining trend of the positive impacts of partial cutting on DBH growth over time or along recovery years, indicating that the growth stimulation effect on residual trees should decline with ecosystem recovery over time, consistent with previous speculations (e.g., Sánchez-Humanes and Espelta, 2011). However, uncertainties remain in the changes of DBH growth after partial cutting. First, the relative changes in DBH growth correlated positively to cutting intensity and negatively to recovery time in general (Table 2), but the relative changes along the cutting intensity gradient in the short term $(<5 \mathrm{yr})$ (Fig. 4) and along recovery time sequences after moderate and heavy cutting were not significant (Fig. 5). Second, large variations were observed in the relative changes of DBH growth, with mean standard error of the relative change reaching up to $10.7 \%$ (Fig. 1). This might suggest that other factors including cutting method, species, and site conditions may exert significant impacts on the magnitude of the relative changes of DBH growth after partial cutting (Skovsgaard, 2009). For example, we found that the DBH growth was more intensive in the broadleaf trees than in conifers compared with the uncut controls, and was lower in subtropical forests than the other forests (Fig. 2), mainly because of the different levels of light improvement for remaining trees after cutting activities (Hale, 2003).

The relative changes in stand basal area and volume following cutting varied significantly along the cutting intensity and recovery years gradients, with the greatest decrease in the short term under heavy cutting (Figs. 4 and 5). This change pattern supports the hypothesis that the impact of partial cutting is relatively short term, with the greatest impacts in the early years after disturbance under heavy disturbance intensity (Amiro et al., 2010; Liu et al., 2011). The return of stand basal area and volume to uncut levels depends strongly 
Table 3. General linear models of potential driving factors predicting the relative changes $(\%)$ for the four variables with sufficient observations $(P<0.001)$.

\begin{tabular}{|c|c|c|}
\hline Indicators & $\mathrm{R}^{2}$ & Liner model \\
\hline DBH growth & $\begin{array}{l}0.13 \\
0.29\end{array}$ & $\begin{array}{l}-1.90 \mathrm{CI}-1.73^{*} \mathrm{RY}+112.87^{* *} \\
12.73 \mathrm{CI}-3.25^{* *} \mathrm{RY}-47.89 \mathrm{C} 1+68.24^{*} \mathrm{C}_{2}+49.18 \mathrm{C}_{3}+24.70 \mathrm{C}_{4}-43.82 \mathrm{C}_{5} \\
+61.17^{* *} \mathrm{~F}_{2}-15.71 \mathrm{DCI}_{1}-2.79 \mathrm{DCI}_{2}+84.47^{*}\end{array}$ \\
\hline Stand BA & $\begin{array}{l}0.43 \\
0.65\end{array}$ & $\begin{array}{l}-54.58^{* *} \mathrm{CI}+0.70^{* *} \mathrm{RY}-11.91^{* *} \\
-49.56^{* *} \mathrm{CI}+0.65^{* *} \mathrm{RY}-4.12 \mathrm{C} 1-35.44^{* *} \mathrm{C}_{2}-22.93^{* *} \mathrm{C}_{3}-25.18^{* *} \mathrm{C}_{4} \\
-36.72^{* *} \mathrm{C}_{5}-20.28^{* *} \mathrm{~F}_{1}-2.51 \mathrm{~F}_{2}+23.18^{* *} \mathrm{DCI}_{1}+17.83^{* *} \mathrm{DCI}_{2}-11.17^{*}\end{array}$ \\
\hline Volume & $\begin{array}{l}0.48 \\
0.76\end{array}$ & $\begin{array}{l}-62.26^{* *} \mathrm{CI}+0.44^{*} \mathrm{RY}-10.63^{* *} \\
-91.85^{* *} \mathrm{CI}+0.87^{* *} \mathrm{RY}-2.79 \mathrm{C} 1+15.85 \mathrm{C}_{2}-4.10 \mathrm{C}_{3}-25.18 \mathrm{C}_{4}+2.17 \mathrm{C}_{5} \\
+1.73 \mathrm{~F}_{2}+29.68^{* *} \mathrm{DCI}_{1}+25.51^{* *} \mathrm{DCI}_{2}-26.26^{*}\end{array}$ \\
\hline AGBC & $\begin{array}{l}0.65 \\
0.76\end{array}$ & $\begin{array}{l}-58.66 \mathrm{CI}^{* *}+2.05 \mathrm{Y}^{* *}-22.73^{* *} \\
-74.79^{* *} \mathrm{CI}+1.85^{* *} \mathrm{RY}+13.26 \mathrm{C} 1+7.74 \mathrm{C}_{2}+8.85 \mathrm{C}_{3}+15.00^{* *} \mathrm{C}_{4}+20.17^{* *} \mathrm{C}_{5} \\
+7.65^{* *} \mathrm{~F}_{2}+3.98 \mathrm{DCI}_{1}+12.57^{*} \mathrm{DCI}_{2}-33.41^{* *}\end{array}$ \\
\hline
\end{tabular}

* Correlation is significant at the 0.05 level ( 2 tailed); ${ }^{* *}$ Correlation is significant at the 0.01 level ( 2 tailed).

The abbreviations are the same as Table 2 .

on cutting intensity, with a longer time needed for a higher intensity (Figs. 4 and 5). These results suggest that the impacts of partial cutting on forest structure decline over time owing to the forest recovery, and that the magnitude of the recovery was closely related to the cutting intensity - both of them were consistent with previous understanding (Juodvalkis et al., 2005).

\subsection{Carbon stock dynamics after partial cutting}

One of the most crucial issues in studying ecological consequences of partial cutting in forests is how it impacts the carbon stocks over years under different disturbance intensities. A conceptual trajectory of $\mathrm{C}$ changes following a cutting is a large pulse of $\mathrm{C}$ loss as a result of the cutting followed by subsequent recovery over time (Liu et al., 2011; Weng et al., 2012; Goetz et al., 2012). The return to pre-cutting levels can take decades and varies with disturbance intensity (Pregitzer and Euskirchen, 2004). Our synthesis corresponds well to this trajectory and suggests that $\mathrm{C}$ storage in aboveground biomass (i.e., AGBC) after partial cutting decreased linearly with cutting intensity (Fig. 4). At the same time, the carbon loss induced by partial cutting recovered with time (Fig. 5), which confirms that partial cutting may only have a short-term negative impact on carbon accumulation in vegetation (Vargas et al., 2009; Amiro et al., 2010). However, we did not find significant recovery trends after lowintensity cutting in our compiled database, suggesting that low cutting effects may be outweighed by the other effects induced by the between-site variations, such as the differences in stand structure, forest type, and stand age (Ryan et al., 2004; Blanco et al., 2006). In addition, it will remain difficult to determine how much time is needed for a complete recovery since there were no observations on AGBC longer than $42 \mathrm{yr}$ in our synthesized database. Using the linear models, we estimated that the AGBC of a temperate deciduous forest requires an average of $31 \mathrm{yr}$ to return to the uncut level following partial cutting with a cutting intensity of $50 \%$ (defined by stand basal area), and it requires $52 \mathrm{yr}$ to recover from clear cutting (cutting intensity is $100 \%$ ). These predictions were comparable to the model study that suggested the period required to replace carbon lost during and after moderate cutting should be within $50 \mathrm{yr}$ and between 50 and $100 \mathrm{yr}$ for clear cutting in ponderosa pine stands in Oregon (Law et al., 2001).

Understory $\mathrm{C}$ was stimulated significantly by partial cutting in all of the studies. This stimulation can be mostly attributed to an increase in the availability of light, water, and nutrients to the understory because of tree removal (Aussenac, 2000; Kleintjes et al., 2004; Deal, 2007). However, the $\mathrm{C}$ increase in understory cannot compensate the $\mathrm{C}$ loss in AGBC since it only accounts for a substantially small proportion of the aboveground biomass in forests as a whole (Gilliam, 2007). In addition, understory would have impacts on residual tree growth through competition for moisture and nutrient.

Soil $\mathrm{C}$ stored in the forest floor reflects the balance between $\mathrm{C}$ input by litterfall, rhizodeposition and cutting residuals, and the $\mathrm{C}$ release during decomposition (Jandl et al., 2007). The removal of overstory trees reduces the annual litterfall input directly (Blanco et al., 2006; Campbell et al., 2009; Kunhamu et al., 2009), which is expected to exert certain negative impacts on the $\mathrm{C}$ stock in the forest floor since the accumulation of annual litterfall is an important component of forest floor $\mathrm{C}$ stock. At the same time, increase in soil surface temperature after partial cutting, which could accelerate the decay rates (Piene and van Cleve, 1978; Kunhamu et al., 2009), might also contribute to the reduction of the 

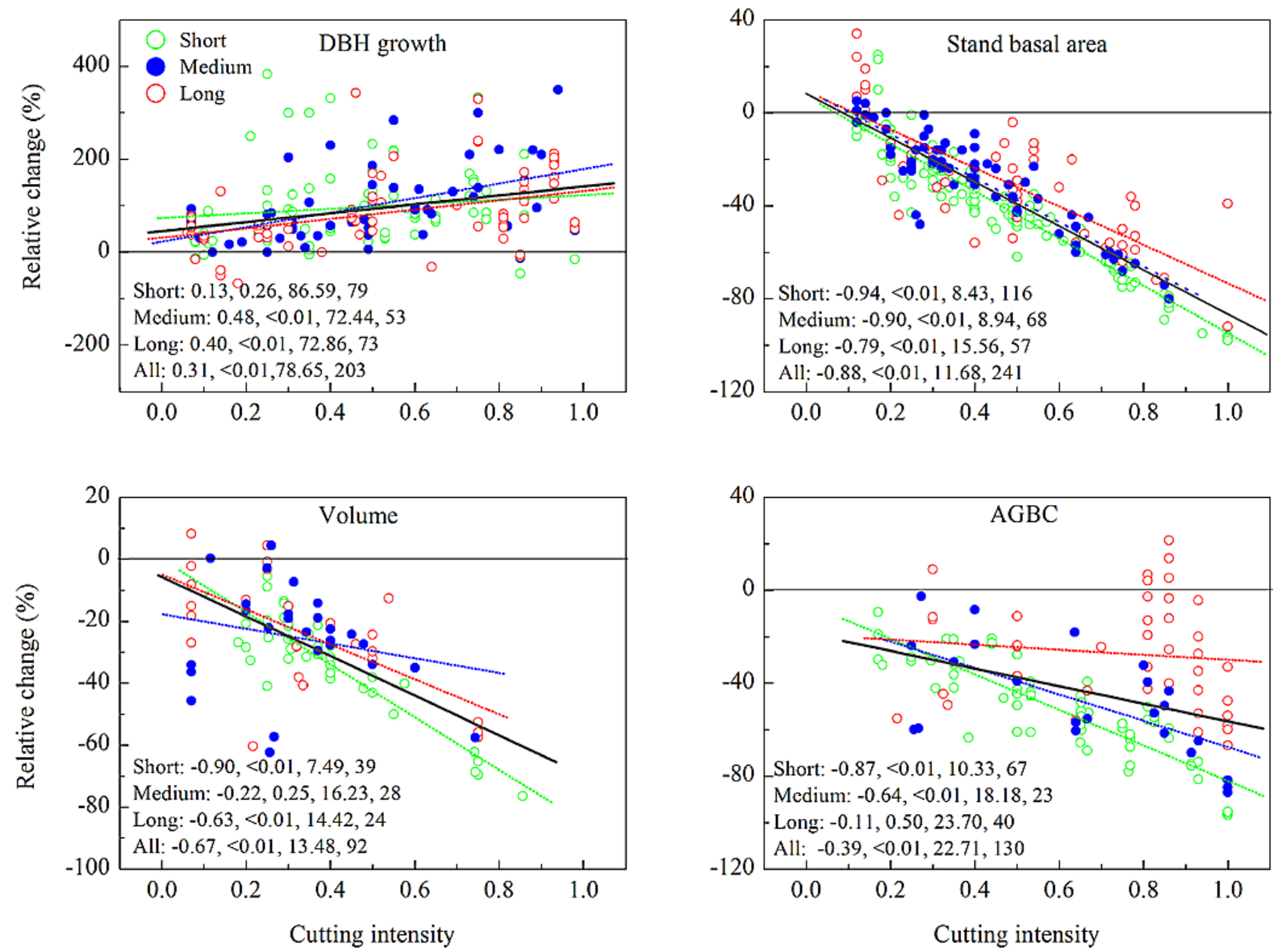

Fig. 4. The relative changes (\%) along the CI gradient where the observations were grouped by the recovery years (RY) since cutting activities into short (green circle: $\mathrm{RY} \leq 5 \mathrm{yr}$ ), medium (blue circle: $5 \mathrm{yr}<\mathrm{RY} \leq 10 \mathrm{yr}$ ), and long (red circle: $\mathrm{RY}>10 \mathrm{yr}$ ) time periods. The dotted lines represent the linear fit curves of short, medium, and long RY with corresponding colors, and the bold black line indicates the linear fit curve of all observations. The correlation coefficient $(R)$, confidence of significance $(P)$, standard error (SE), and the number of observations $(N)$ of each linear regression analysis are shown at the bottom of figure panel. Five observations that are larger than $400 \%$ were not shown in the figure panel of DBH growth.

C stock on the forest floor. However, our synthesis indicates the change in the forest floor $\mathrm{C}$ stock was not significantly affected by cutting. This finding can be largely explained by the fact that the negative effects of decreased $\mathrm{C}$ input from litterfall together with the increase in the decomposition rate of the forest floor $\mathrm{C}$ may have been compensated by the immediate $\mathrm{C}$ input of cutting residues into the forest floor (de Wit and Kvindesland, 1999), and the following ecosystem recovery over time.

Our synthesis indicates that the change in mineral soil C after partial cutting was not significant, consistent with the findings from the two previous meta-analyses (Johnson and Curtis, 2001; Nave et al., 2010). The C stock in mineral soil varies greatly among sites and is primarily determined by other influences such as soil chemistry and physical characteristics (Nave et al., 2010).

It should be noted that the biomass $\mathrm{C}$ removed generally did not return immediately to the atmosphere but rather re- mained stored in a durable status such as in wood products (Fahey et al., 2009), which (if long lived) can be considered a $\mathrm{C}$ sink (Pacala et al., 2007). The removed biomass was one major contributor to global energy supply (Berndes et al., 2003). Moreover, it's widely accepted that partial cutting alters species composition and stand structure, which can provide many benefits, such as enhancement of wood products and reduction of fire risk (Kolb et al., 1998; Harvey et al., 2002; Frey et al., 2003; McDowell et al., 2006; Campbell et al., 2009). Thus, the immediate AGBC loss induced by partial cutting can be repaid in other terms of forest services and functions.

\subsection{Implications and challenges}

It is evident that cutting practice significantly affects the structure and C stocks of the forest ecosystem. Because partial cutting will likely continue as a major type of silvicultural 

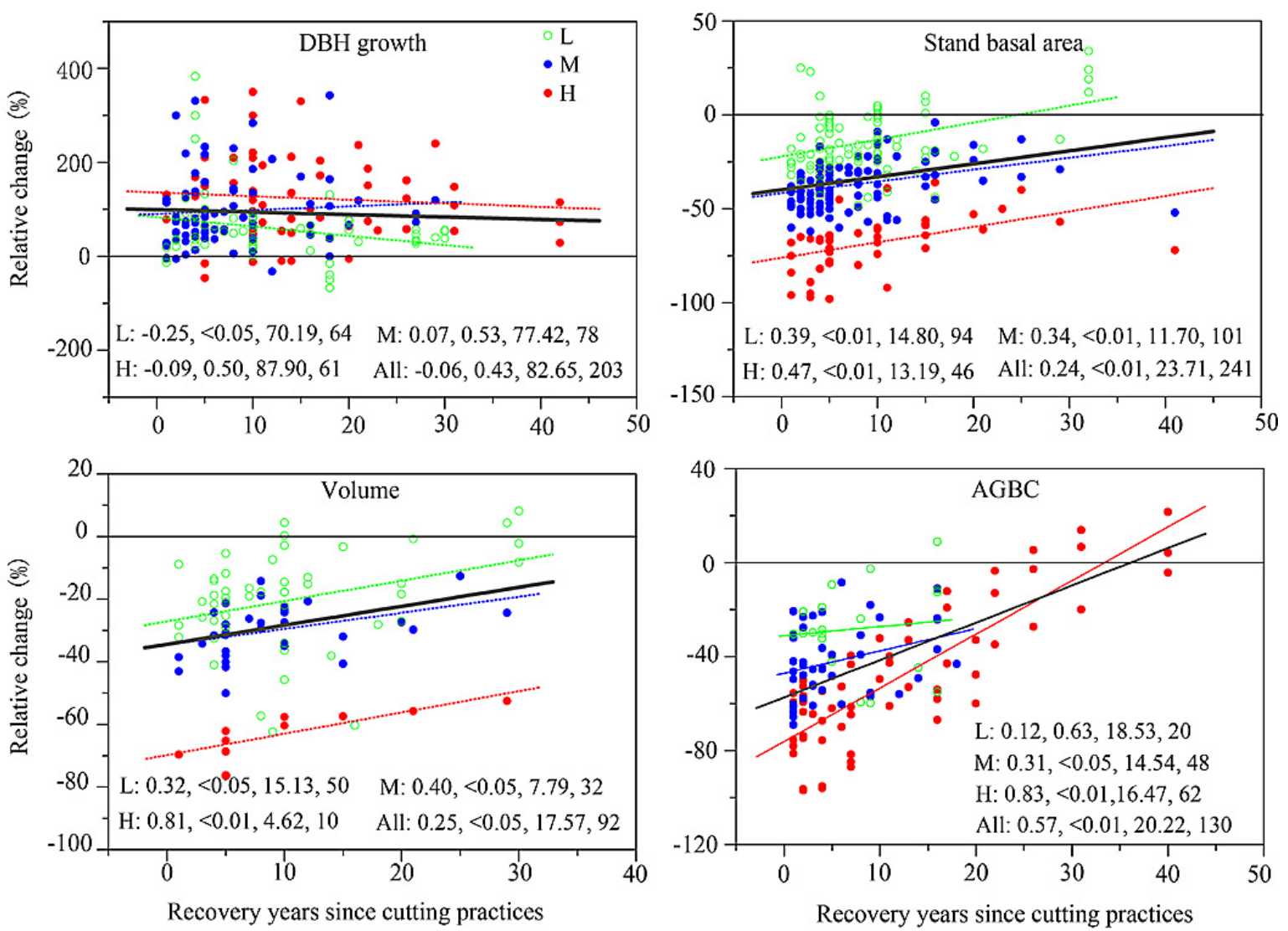

Fig. 5. The relative changes (\%) along the RY gradient, where the observations were grouped into L (green circle), M (blue circle), and $H$ (red circle) cutting levels. The dotted lines represent the linear fit curves of the cutting under L, M, and $\mathrm{H}$ intensities with corresponding colors, and the bold black line indicates the linear fit curve of all cutting (All). The $R, P, \mathrm{SE}$ and $N$ of each linear regression analysis are shown at the bottom of each figure panel. Five observations that are larger than $400 \%$ were not shown in the figure panel of DBH growth.

treatment and the demand for timber products continues to rise, forest management practices should be implemented in a way that reduces the negative impacts on forest functions and improves sustainability. Our meta-analysis confirms that $\mathrm{C}$ storage in the forest sector can be enhanced either by increasing the time between cutting activities to allow sufficient time for forests to recover, or reducing the cutting intensity during each cutting activity (Harmon et al., 2009). For instance, Øyen and Nilsen (2002) reported that the cutting intensity, defined by volume, should not be more than $65 \%$ in southeast Norway in order to keep the forest biomass sustainable, given a cutting cycle of less than $50 \mathrm{yr}$. If managed sustainably, partial cutting could simultaneously preserve remaining native forests and function as a long-term carbon sink (Berthrong et al., 2009; Powers et al., 2012), and even increase $\mathrm{C}$ storage while providing as many forest products as the traditional clear cutting (Harmon and Marks, 2002).

However, several challenges still preclude our comprehensive understanding of the dynamics in forest ecosystems affected by partial cutting. First, large geographic bias existed in the field observations we have assembled (Figs. S1 and S3). About $63 \%$ of the case studies were from North America, but their forested area only accounts for $17 \%$ of the world's total forest area (FAO, 2010). Comparatively, the number of studies was much lower in Africa and South America (Fig. S3). Second, the depth of the mineral soil was restricted to the surface soil with a depth of $0-15 \mathrm{~cm}$ in our database. However, it has been recognized that the relative change of carbon stock might be equally important in the subsoil (Don et al., 2011). Third, uncertainties existed in observed variables across study sites, particularly for DBH growth, characterized by low correlation coefficients between its changes and driving factors included in this synthesis (i.e., cutting intensity, recovery time, forest type, climate zone, and cutting intensity definition) for most cases. Other factors such as cutting methods (Johnson et al., 2002; Blanc et al., 2009), post-treatment methods (Olsson and Staaf, 1995), stand age (Juodvalkis et al., 2005), and site conditions (Skovsgaard, 2009) may also exert significant impacts on the responses of forest ecosystems to partial cutting. However, because of the lack of detailed descriptions for these variables in many studies within our database, their 
impacts could not be analyzed in this study. Fourth, longterm experiments are rare and urgently needed. Many model studies suggested that partial cutting increased the ecosystem carbon in the long term (Garcia-Gonzalo et al., 2007; Taylor et al., 2008; Thiffault et al., 2011). However, it is still difficult to determine how long a complete recovery would take due to the lack of long-term experiments. Finally, the remote sensing techniques are a cost-effective way to detect largescale changes in both forest area and carbon storage (Skole and Tucker, 1993; Achard et al., 2002). However, it is difficult to isolate the effects of partial cutting from the other disturbances using remote sensing (Houghton, 2005; Asner et al., 2005; Peres et al., 2006; Liu et al., 2011). For a better understanding of the consequences of partial cutting at regional or global scales, both the inventories and remotely sensed datasets may be needed (Goetz et al., 2012).

\section{Summary}

This study provides a comprehensive assessment of the dynamics of several key forest properties following partial cutting. Our results show that partial cutting decreased stand basal area and volume greatly, but it can promote the growth of residual trees. Partial cutting reduced AGBC significantly while greatly increased $\mathrm{C}$ storage in the understory. The $\mathrm{C}$ stocks in the forest floor and in mineral soil were not significantly affected by partial cutting. Although partial cutting generally reduced $\mathrm{C}$ storage in aboveground biomass by removing individual trees from a forest, it can provide many benefits in other ways.

For the four variables with sufficient observations (DBH growth, stand basal area, volume, and AGBC), the magnitude of the relative change increased linearly with cutting intensity and decreased linearly over time. In addition to the impacts of cutting intensity and recovery years, other factors, such as climate zone, forest type, and cutting intensity definition, were also found responsible for the observed variations of these four variables among study sites. Nevertheless, uncertainties existed in the forest responses to partial cutting, in particular for DBH growth, because a large fraction of their fluctuations remains unexplained, suggesting the importance of considering more factors in future syntheses.

Our results highlight the various responses of the different structural characteristics and $\mathrm{C}$ stock components to partial cutting and the intrinsic nature of ecosystem resilience after the disturbance. Yet the data extracted from various studies did not enable us to determine how long it would take for a complete recovery under different disturbance levels. To further our understanding of the impacts of partial cutting, we recommend that future efforts should be tailored to reduce the geographic bias of field studies and increase the depth of soil sampling and the duration of the experiments.

\section{Supplementary material related to this article is available online at: http://www.biogeosciences.net/10/ 3691/2013/bg-10-3691-2013-supplement.pdf.}

Acknowledgements. This study was supported by the National Basic Research Program of China on Global Change (\#2010CB50600), the National Natural Science Foundation of China (\#41071050 and \#31021001), and the US Geological Survey's Land Carbon Project and the Land Change Science (LCS) Program. The authors are grateful to editors and two anonymous reviewers for their constructive comments.

Edited by: J. Xiao

\section{References}

Achard, F., Eva, H. D., Stibig, H. J., Mayaux, P., Gallego, J., Richards, T., and Malingreau, J. P.: Determination of deforestation rates of the world's humid tropical forests, Science, 297, 999-1002, 2002.

Amiro, B. D., Barr, A. G., Barr, J. G., Black, T. A., Bracho, R., Brown, M., Chen, J., Clark, K. L., Davis, K. J., Desai, A. R., Dore, S., Engel, V., Fuentes, J. D., Goldstein, A. H., Goulden, M. L., Kolb, T. E., Lavigne, M. B., Law, B. E., Margolis, H. A., Martin, T., McCaughey, J. H., Misson, L., Montes-Helu, M., Noormets, A., Randerson, J. T., Starr, G., and Xiao, J.: Ecosystem carbon dioxide fluxes after disturbance in forests of North America, J. Geophys. Res., 115, G00K02, doi:10.1029/2010JG001390, 2010.

Asner, G. P., Knapp, D. E., Broadbent, E. N., Oliveira, P. J. C., Keller, M., and Silva, J. N.: Selective logging in the Brazilian Amazon, Science, 310, 480-482, 2005.

Aussenac, G.: Interactions between forest stands and microclimate: ecophysiological aspects and consequences for silviculture, Ann. Forest Sci., 57, 287-301, 2000.

Berndes, G., Hoogwijk, M., and van den Broek, R.: The contribution of biomass in the future global energy system: a review of 17 studies, Biomass Bioenergy, 25, 1-28, 2003.

Berthrong, S. T., Jobbágy, E., and Jackson, R. B.: A global metaanalysis of soil exchangeable cations, $\mathrm{pH}$, carbon, and nitrogen with afforestation, Ecol. Appl., 19, 2228-2241, 2009.

Blanc, L., Echard, M., Herault, B., Bonal, D., Marcon, E., Chave, J., and Baraloto, C.: Dynamics of aboveground carbon stocks in a selectively logged tropical forest, Ecol. Appl., 19, 1397-1404, 2009.

Blanco, J. A., Imbert, J. B., and Castillo, F. J.: Influence of site characteristics and thinning intensity on litterfall production in two Pinus sylvestris L. forests in the western Pyrenees, Forest Ecol. Manag., 237, 342-352, 2006.

Bunker, D. E., DeClerck, F., Bradford, J. C., Colwell, R. K., Perfecto, I., Phillips, O. L., Sankaran, M., and Naeem, S.: Species loss and aboveground carbon storage in a tropical forest, Science, 310, 1029-1031, 2005. 
Campbell, J., Alberti, G., Martin, J., and Law, B. E.: Carbon dynamics of a ponderosa pine plantation following a thinning treatment in the northern Sierra Nevada, Forest Ecol. Manag., 257, 453463, 2009.

Chan, S. S., Larson, D. J., Maas-Hebner, K. G., Emmingham, W. H., Johnston, S. R., Mikowski, and D. A.: Overstory and understory development in thinned and under planted Oregon Coast Range Douglas-fir stands, Can. J. For. Res., 36, 2696-2711, 2006.

Curtis, R. O., Marshall, D. D., and Bell, J. F.: LOGS: a pioneering example of silvicultural research in coast Douglas-fir, J. Forest., 95, 19-25, 1997.

De Wit, H. A. and Kvindesland, S.: Carbon stocks in Norwegian forest soils and effects of forest management on carbon storage, Rapport Fra Skogforskningen, S14, 52, 1999.

Deal, R. L.: Management strategies to increase stand structural diversity and enhance biodiversity in coastal rainforests of Alaska, Biol. Conserv., 137, 520-532, 2007.

DeFries, R. S., Rudel, T., Uriarte, M., and Hansen, M.: Deforestation driven by urban population growth and agricultural trade in the twenty-first century, Nat. Geosci., 3, 178-181, 2010.

Don, A., Schumacher, J., and Freibaue, A.: Impact of tropical landuse change on soil organic carbon stocks - a meta-analysis, Glob. Change Biol., 17, 1658-1670, 2011.

Dwyer, J. M., Fensham, R., and Buckley, Y. M.: Restoration thinning accelerates structural development and carbon sequestration in an endangered Australian ecosystem, J. Appl. Ecol., 47, 681691, 2010.

Fahey, T. J., Woodbury, P. B., Battles, J. J., Goodale, C. L., Hamburg, S. P., Ollinger, S. V., and Woodall, C. W.: Forest carbon storage: ecology, management, and policy. Front. Ecol. Environ., 8, 245-252, 2009.

FAO: Global Forest Resources Assessment 2010 Main Report, Rome, FAO, 2010.

Frey, B. R., Lieffers, V. J., Munson, A. D., and Blenis, P. V.: The influence of partial harvesting and forest floor disturbance on nutrient availability and understory vegetation in boreal mixedwoods, Can. J. For. Res., 33, 1180-1188, 2003.

Garcia-Gonzalo, J., Peltola, H., Briceño-elizondo, E., and Kellomäki, S.: Changed thinning regimes may increase carbon stock under climate change: A case study from a Finnish boreal forest, Climatic Change, 81, 431-454, 2007.

Gilliam, F. S.: The ecological significance of the herbaceous layer in temperate forest ecosystems, BioScience, 57, 845-858, 2007.

Goetz, S., Bond-Lamberty, B., Law, B., Hicke, J., Huang, C., Houghton, R., McNulty, S., O’Halloran, T., Harmon, M., and Meddens, A.: Observations and assessment of forest carbon dynamics following disturbance in North America, J. Geophys. Res., 117, G02022, doi:10.1029/2011JG001733, 2012.

Guariguata, M. R.: Early response of selected tree species to liberation thinning in a young secondary forest in Northeastern Costa Rica, Forest Ecol. Manag., 124, 255-261, 1999.

Gujarati, D.: Use of dummy variables in testing for equality between sets of coefficients in linear regressions: a generalization, Am. Stat., 24, 18-22, 1970.

Gundale, M. J., DeLuca, T. H., Fiedler, C. E., Ramsey, P. W., Harrington, M. G., Gannon, J. E.: Restoration treatments in a Montana ponderosa pine forest: Effects on soil physical, chemical and biological properties, Forest Ecol. Manag., 213, 25-38, 2005.
Guo, L. B. and Gifford, R. M.: Soil carbon stocks and land use change: a meta analysis, Glob. Change Biol., 8, 345-360, 2002.

Gurevitch, J. and Hedges, L. V.: Meta-analysis: combining the results of independent experiments, in: Design and analysis of ecological experiments, edited by: Scheiner, S. M. and Gurevitch, J., Oxford, UK, Oxford University Press, 347-369, 2001.

Hale, S. E.: The effect of thinning intensity on the below-canopy light environment in a Sitka spruce plantation, Forest Ecol. Manag., 179, 341-349, 2003.

Harmon, M. E. and Marks, B.: Effects of silvicultural practices on carbon stores in Douglas-fir - western hemlock forests in the Pacific Northwest, U.S.A.: results from a simulation model, Can. J. For. Res., 32, 863-877, 2002.

Harmon, M. E., Moreno, A., and Domingo, J. B.: Effects of partial harvest on the carbon stores in Douglas-fir/western hemlock forests: a simulation study, Ecosystems, 12, 777-791, 2009.

Harvey, B. D., Leduc, A., Gauthier, S., and Bergeron, Y.: Standlandscape integration in natural disturbance-based management of the southern boreal forest, Forest Ecol. Manag., 155, 369-385, 2002.

Horner, G. J., Baker, P. J., Nally, R. M., Cunningham, S. C., Thomson, J. R., and Hamilton, F.: Forest structure, habitat and carbon benefits from thinning floodplain forests: Managing early stand density makes a difference, Forest Ecol. Manag., 259, 286-293, 2010.

Houghton, R. A.: Aboveground forest biomass and the global carbon balance, Glob. Change Biol., 11, 945-958, 2005.

Huang, M. and Asner, G. P.: Long-term carbon loss and recovery following selective logging in Amazon forests, Global Biogeochem. Cy., 24, GB3028, doi:10.1029/2009GB003727, 2010.

Jandl, R., Lindner, M., Vesterdal, L., Bauwens, B., Baritz, R., Hagedorn, F., Johnson, D. W., Minkkinen, K., and Byrne, K. A.: How strongly can forest management influence soil carbon sequestration?, Geoderma, 137, 253-268, 2007.

Johnson, D. W. and Curtis, P. S.: Effects of forest management on soil $\mathrm{C}$ and $\mathrm{N}$ storage: meta analysis, Forest Ecol. Manag., 140, 227-238, 2001.

Johnson, D. W., Knoepp, J. D., Swank, W. T., Shan, J., Morris, L. A., Van Lear, D. H., and Kapeluck, P. R.: Effects of forest management on soil carbon: results of some long-term resampling studies, Environ. Pollut., 116, S201-S208, 2002.

Juodvalkis, A., Kairiukstis, L., and Vasiliauskas, R.: Effects of thinning on growth of six tree species in north-temperate forests of Lithuania, Eur. J. Forest Res., 124, 187-192, 2005.

Kleintjes, P. K., Jacobs, B. F., and Fettig, S. M.: Initial response of butterflies to an overstory reduction and slash mulching treatment of a degraded piñon-juniper woodland, Restor. Ecol., 12, 231238, 2004.

Kolb, T. E., Holmberg, K. M., Wagner, M. R., and Stone, J. E.: Regulation of ponderosa pine foliar physiology and insect resistance mechanisms by basal area treatments, Tree Physiol., 18, 375-381, 1998.

Kunhamu, T. K., Kumar, B. M., and Viswanath, S.: Does thinning affect litterfall, litter decomposition, and associated nutrient release in Acacia mangium stands of Kerala in peninsular India?, Can. J. For. Res., 39, 792-800, 2009.

Laganière, J., Angers, D. A., and Paré, D.: Carbon accumulation in agricultural soils after afforestation: a meta-analysis, Glob. Change Biol., 16, 439-45, 2010. 
Law, B. E., Thornton, P. E., Irvine, J., Anthoni, P. M., and Vantuyl, S.: Carbon storage and fluxes in ponderosa pine forests at different developmental stages, Glob. Change Biol., 7, 755-777, 2001.

Lee, J., Morrison, I. K., Leblanc, J. D., Dumas, M. T., and Cameron, D. A.: Carbon sequestration in trees and regrowth vegetation as affected by clearcut and partial cut harvesting in a second-growth boreal mixedwood, Forest Ecol. Manag., 169, 83-101, 2002.

Lindquist, J.: The Whiskey Springs Redwood Commercial Thinning Study: A 29-Year Status Report (1970 to 1999), in: Proceedings of the redwood region forest science symposium: What does the future hold? edited by: Standiford, R. B., Giusti, G. A., Valachovic, Y., Zielinski, W. J., and Furniss, M. J., Gen. Tech. Rep. PSW-GTR-194. Albany, CA, Pacific Southwest Research Station, Forest Service, US Department of Agriculture, 305-316, 2007.

Liu, S., Bond-Lamberty, B., Hicke, J. A., Vargas, R., Zhao, S., Chen, J., Edburg, S. L., Hu, Y., Liu, J., McGuire, A. D., Xiao, J., Keane, R., Yuan, W., Tang, J., Luo, Y., Potter, C., and Oeding, J.: Simulating the impacts of disturbances on forest carbon cycling in North America: Processes, data, models, and challenges, J. Geophys. Res., 116, G00K08, doi:10.1029/2010JG001585, 2011.

Luo, Y., Hui, D., and Zhang, D.: Elevated $\mathrm{CO}_{2}$ stimulates net accumulations of carbon and nitrogen in land ecosystems: a metaanalysis, Ecology, 87, 53-63, 2006.

Masek, J. G., Cohen, W. B., Leckie, D., Wulder, M. A., Vargas, R., de Jong, B., Healey, S., Law, B., Birdsey, R., Houghton, R. A., Mildrexler, D., Goward, S., and Smith, W. B.: Recent rates of forest harvest and conversion in North America, J. Geophys. Res., 116, G00K03, doi:10.1029/2010JG001471, 2011.

McDowell, N. G., Adams, H. A., Bailey, J. D., Hess, M., and Kolb, T. E.: Homeostatic maintenance of ponderosa pine gas exchange in response to stand density changes, Ecol. Appl., 16, 11641182, 2006.

Navarro, F. B., Jiménez, M. N., Cañadas, E. M., Gallego, E., Terrón, L., and Ripoll, M. A.: Effects of different intensities of overstory thinning on tree growth and understory plant-species productivity in a semi-arid Pinus halepensis Mill. Afforestation, Forest Syst., 19, 410-417, 2010.

Nave, L. E., Vance, E. D., Swanston, C. W., and Curtis, P. S.: Harvest impacts on soil carbon storage in temperate forests, Forest Ecol. Manag., 259, 857-866, 2010.

Olsson, B. A. and Staaf, H.: Influence of harvesting intensity of logging residues on ground vegetation in coniferous forests, J. Appl. Ecol., 32, 640-654, 1995.

Øyen, B. H. and Nilsen, P.: Growth effects after mountain forest selective cutting in southeast Norway, Forestry, 75, 401-410, 2002.

Pacala, S., Birdsey, R. A., Bridgham, S. D., Conant, R. T., Davis, K., Hales, B., Houghton, R. A., Jenkins, J. C., Johnston, M., and Marland, G.: The North American carbon budget past and present. The First State of the Carbon Cycle Report (SOCCR): The North American Carbon Budget and Implications for the Global Carbon Cycle, Departments of Energy and Commerce and NASA, 2007.

Pan, Y., Birdsey, R. A., Fang, J., Houghton, R., Kauppi, P. E., Kurz, W. A., Phillips, O. L., Shvidenko, A., Lewis, S. L., Canadell, J. G., Ciais, P., Jackson, R. B., Pacala, S., McGuire, A. D., Piao, S., Rautiainen, A., Sitch, S., and Hayes, D.: A large and persistent carbon sink in the world's forests, Science, 333, 988-993, 2011.
Peña-Claros, M., Fredericksen, T. S., Alarcón, A., Blate, G. M., Choque, U., Leaño, C., Licona, J.C., Mostacedo, B., Pariona, W., Villegas, Z., and Putz, F. E.: Beyond reduced-impact logging: Silvicultural treatments to increase growth rates of tropical trees, Forest Ecol. Manag., 256, 1458-1467, 2008.

Peres, C. A., Barlow, J., and Laurance, W. F.: Detecting anthropogenic disturbance in tropical forests, Trends Ecol. Evol., 21, 227-229, 2006.

Piene, H. and van Cleve, K.: Weight loss of litter and cellulose bags in a thinned white spruce forest in interior Alaska, Can. J. For. Res., 8, 42-46, 1978.

Powers, J. S., Corre, M. D., Twine, T. E., and Veldkamp, E.: Geographic bias of field observations of soil carbon stocks with tropical land-use changes precludes spatial extrapolation, P. Natl. Acad. Sci., 108, 1-5, 2011.

Powers, M. D., Kolka, R. K., Bradford, J. B., Palik, B. J., Fraver, S., and Jurgensen, M. F.: Carbon stocks across a chronosequence of thinned and unmanaged red pine (Pinus resinosa) stands, Ecol. Appl., 22, 1297-1307, 2012.

Pregitzer, K. S. and Euskirchen, E. S.: Carbon cycling and storage in world forests: Biome patterns related to forest age, Glob. Change Biol., 10, 2052-2077, 2004.

Reich, P. B.: Taking stock of forest carbon, Nat. Clim. Chang., 1,346-347, 2011.

Ryan, M. G., Binkley, D., Fownes, J. H., Giardina, C., and Senock, R. S.: An experimental test of the causes of forest growth decline with stand age, Ecol. Monogr., 74, 393-414, 2004.

Sánchez-Humanes, B. and Espelta, J. M.: Increased drought reduces acorn production in Quercus ilex coppices: thinning mitigates this effect but only in the short term, Forestry, 84, 73-82, 2011.

Sawadogo, L., Tiveau, D., and Nygård, R.: Influence of selective tree cutting, livestock and prescribed fire on herbaceous biomass in the savannah woodlands of Burkina Faso, West Africa, Agr. Ecosyst. Environ., 105, 335-345, 2005.

Scheller, R. M., Hua, D., Bolstad, P. V., Birdsey, R. A., and Mladenoff, D. J.: The effects of forest harvest intensity in combination with wind disturbance on carbon dynamics in Lake States Mesic Forests, Ecol. Model., 222, 144-153, 2011.

Skole, D. and Tucker, C.: Tropical deforestation and habitat fragmentation in the Amazon: satellite data from 1978 to 1988, Science, 260, 1905-1910, 1993.

Skovsgaard, J. P.: Analyzing effects of thinning on stand volume growth in relation to site conditions: A case study for even-aged Sitka spruce (Picea sitchensis (Bong.) Carr.), Forestry, 82, 87104, 2009.

Smith, D. M.: Effect of method of thinning on wood production in a red pine plantation, North. J. Appl. For., 20, 39-42, 2003.

Taylor, A. R., Wang, J. R., and Kurz, W. A.: Effects of harvesting intensity on carbon stocks in eastern Canadian red spruce (Picea rubens) forests: An exploratory analysis using the CBM-CFS3 simulation model, Forest Ecol. Manag., 255, 3632-3641, 2008.

Thiffault, E., Hannam, K. D., Paré, D., Titus, B. D., Hazlett, P. W., Maynard, D. G., and Brais, S.: Effects of forest biomass harvesting on soil productivity in boreal and temperate forests - A review, Environ. Rev., 19, 278-309, 2011.

Vargas, R., Allen, E. B., and Allen, M. F.: Effects of Vegetation Thinning on Above- and Belowground Carbon in a Seasonally Dry Tropical Forest in Mexico, Biotropica, 41, 302-311, 2009. 
Vesala, T., Suni, T., Rannik, U., Keronen, P., Markkanen, T., Sevanto, S., Grönholm, T., Smolander, S., Kulmala, M., Ilvesniemi, H., Ojansuu, R., Uotila, A., Levula, J., Mäkelä, A., Pumpanen, J., Kolari, P., Kulmala, L., Altimir, N., Berninger, F., Nikinmaa, E., and Hari, P.: Effect of thinning on surface fluxes in a boreal forest, Global Biogeochem. Cy., 19, GB2001, doi:10.1029/2004GB002316, 2005.

Walter, S. T. and Maguire, C. C.: Conifer response to three silvicultural treatments in the Oregon Coast Range foothills, Can. J. For. Res., 34, 1967-1978, 2004.
Weng, E., Luo, Y., Wang, W., Wang, H., Hayes, D.J., McGuire, A.D., Hastings, A., and Schimel, D. S.: Ecosystem carbon storage capacity as affected by disturbance regimes: A general theoretical model, J. Geophys. Res., 117, G03014, doi:10.1029/2012JG002040, 2012.

Yang, A. R., Son, Y., Noh, N. J., Lee, S. K., Jo, W., Son, J. A., Kim, C., Bae, S. W., Lee, S. T., Kim, H. S., and Hwang, J.: Effect of thinning on carbon storage in soil, forest floor and coarse woody debris of Pinus densiflora stands with different stand ages in Gangwon-do, central Korea, For. Sci. Technol., 7, 30-37, 2011. 